\title{
Formation of metastable calcite-type barium carbonate during low-temperature decomposition of (Ba,Ti)- precursor complexes
}

Vladislav Ischenko, Jörg Woltersdorf, Eckhard Pippel, Roberto Köferstein, Hans-Peter Abicht

Solid State Sciences 9 (2007) 303e309

doi:10.1016/j.solidstatesciences.2007.02.003

\begin{abstract}
(Ba,Ti)-precursor complexes, important for the production of advanced $\mathrm{BaTiO}_{3}$ perovskitetype materials, undergo structural transformations and complex reactions during their thermal decomposition. Based on XRD phase analysis, combined with Rietveld refinement of crystal structure data, and on IR analysis, the intermediate formation of calcite-type $\mathrm{BaCO}_{3}$ is evidenced, which can be explained by the stabilization of this metastable modification in the form of an oxycarbonate phase down to room temperature. Two possible processes, leading to such an oxycarbonate, are discussed: (i) partial substitution of $\mathrm{CO}_{3}{ }^{2-}$ by $\mathrm{O}^{2-}$ in the anionic sublattice, and (ii) topotaxial formation of calcite-type structural domains of $\mathrm{BaCO}_{3}$ by templating with oxygen-deficient titanates, resulting in the oxide-carbonate intergrowth structures.
\end{abstract}

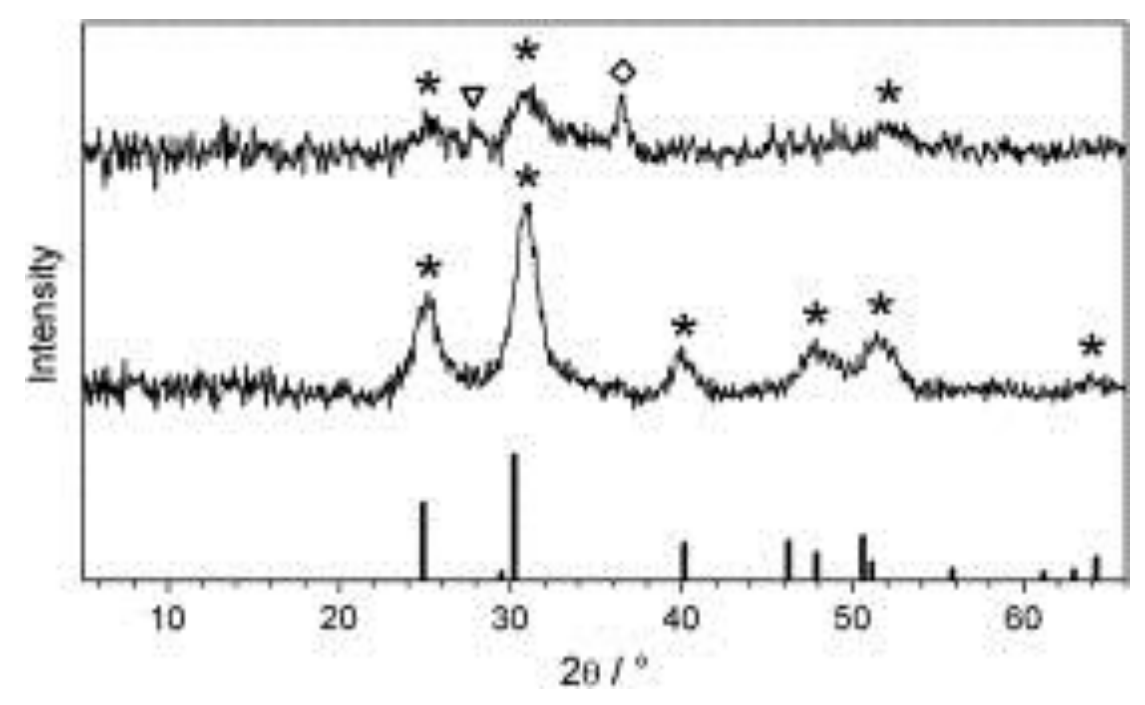




\title{
Formation of metastable calcite-type barium carbonate during low-temperature decomposition of (Ba,Ti)-precursor complexes
}

\author{
Vladislav Ischenko ${ }^{\mathrm{a}}$, Jörg Woltersdorf ${ }^{\mathrm{a}}{ }_{*}$, Eckhard Pippel ${ }^{\mathrm{a}}$, \\ Roberto Köferstein ${ }^{b}$, Hans-Peter Abicht ${ }^{b}{ }_{*}$ \\ ${ }^{a}$ Max-Planck-Insitut fu“ r Mikrostrukturphysik, Weinberg 2, D-06120 Halle, Germany \\ ${ }^{\mathrm{b}}$ Fachbereich Chemie, Martin-Luther-Universita" t, Kurt-Mothes Str. 2, D-06120 Halle, Germany
}

Dedicated to Professor Dr. Dr. h.c. mult. Hellmut Fischmeister on the occasion of his 80th birthday.

\begin{abstract}
(Ba,Ti)-precursor complexes, important for the production of advanced $\mathrm{BaTiO}_{3}$ perovskite-type materials, undergo structural transformations and complex reactions during their thermal decomposition. Based on XRD phase analysis, combined with Rietveld refinement of crystal structure data, and on IR analysis, the intermediate formation of calcite-type $\mathrm{BaCO}_{3}$ is evidenced, which can be explained by the stabilization of this metastable modification in the form of an oxycarbonate phase down to room temperature. Two possible processes, leading to such an oxycarbonate, are discussed: (i) partial substitution of $\mathrm{CO}_{3}{ }^{2-}$ by $\mathrm{O}^{2-}$ in the anionic sublattice, and (ii) topotaxial formation of calcitetype structural domains of $\mathrm{BaCO}_{3}$ by templating with oxygen-deficient titanates, resulting in the oxide-carbonate intergrowth structures.
\end{abstract}

Keywords: Oxycarbonate; Barium titanate; Perovskite; Templating; Thermal decomposition; X-ray diffraction

\section{Introduction}

Recently, the small class of oxycarbonates gained growing attention. The introduction of carbonate anions into the crystal structure of oxides turned out to be very advantageous for the tuning of the properties of different advanced materials, such as high-temperature superconductors [1-6], red- and greenemitting phosphors [7-12], and carbon dioxide sensors $[13,14]$.

Moreover, the possible formation of metastable oxycarbonates in the intermediate stages may be expected to play an important role during preparation of oxide ceramics by thermal decomposition, governing the reaction mechanism and kinetics.

\footnotetext{
* Corresponding authors.

E-mail addresses: ischenko@mpi-halle.de (V. Ischenko), wolt@mpi-halle.

de (J. Woltersdorf), epip@mpi-halle.de (E. Pippel), roberto.koeferstein@chemie.uni-halle.de (R. Köferstein), hans-peter.abicht@chemie.uni-halle.de (H.-P. Abicht).
}

This is of special interest in case of processing routes with com-plex precursors having organic ligands, and which undergo thermal decompositions to form ceramic powders. Particularly for alkaline earth titanates and zirconates, commonly used as refractory materials, supporting layers or piezoelectric materials, the formation of oxycarbonate phases during the thermal de-composition of mixed precursor complexes might be expected.

Following our previous investigations on the different stages of thermal decomposition processes [15], in this contribution we concentrate on the Ba-Ti-C-O-(H) chemical system and discuss the intermediate phases, which can be experimentally observed during synthesis of perovskite-type barium titanate $\mathrm{BaTiO}_{3}$.

The existence of barium oxycarbonate as the structurally simplest oxycarbonate in this system has not been confirmed in the literature until now. More interesting is, however, the possibility to form mixed alkaline earth/transition metal oxycarbonates based on the perovskite-type crystal structure. 
There are few examples in the literature [16-21], showing that some $\mathrm{BO}_{6}$-octahedra in $\mathrm{ABO}_{3}$ perovskites may be replaced by $\mathrm{CO}_{3}{ }_{3}$ anions. This occurs, however, at the expense of the formation of oxygen vacancies and via reduction of the oxidation degree from $\mathrm{B}^{4+}$ to $\mathrm{B}^{3+}$ in $\mathrm{A}^{\mathrm{II}} \mathrm{B}^{\mathrm{IV}} \mathrm{O}_{3}$ perovskites. The formation of such oxycarbonates has been described for $\mathrm{A}_{4}^{\mathrm{II}} \mathrm{B}^{\mathrm{III}}{ }_{2} \mathrm{O}_{6}\left(\mathrm{CO}_{3}\right)$ compounds [16-21], appertaining to the family of Ruddlesdene Popper (RP) perovskite-based structures [22,23], which are composed of a sequence of $n$ perovskitic layers separated by a non-perovskitic interlayer (accordingly $\mathrm{n}=\infty$ corresponds to a pure perovskite), and which can produce solid solutions with the related $\mathrm{A}_{4}^{\mathrm{II}} \mathrm{B}^{\mathrm{IV}}{ }_{3} \mathrm{O}_{10}$ RP-perovskites. The positions $\mathrm{A}$ in their crystal structure are generally limited to $\mathrm{Sr}$ or $\mathrm{Ba}$, while positions $\mathrm{B}$ can be occupied by $\mathrm{Fe}, \mathrm{Mn}, \mathrm{Co}, \mathrm{In}, \mathrm{Ni}, \mathrm{Cu}$, and some-times by their mixtures. It is still an open question whether metastable crystalline phases of this type, including $\mathrm{Ti}$ in a lower oxidation state, can exist in the Ba-Ti-C-O chemical system.

In the last decade some indications of a crystalline intermediate phase observed by XRD during thermal decomposition of precursor complexes were reported [24-28], and the formation of $(\mathrm{Ba}, \mathrm{Ti})$-mixed oxycarbonate with the tentative formula " $\mathrm{Ba}_{2} \mathrm{Ti}_{2} \mathrm{O}_{5} \mathrm{CO}_{3}$ "' has been proposed, based on the bulk chemical analysis data.

In our previous contribution [15], we have reported, however, on a definite component segregation, which was observed on the nanometer scale, during the thermal decomposition of precursor complexes and resulted in the formation of Ba-rich and Ti-rich phases. Only the Ba-rich phase has been found to be predominantly crystalline in the intermediate products of the thermal decomposition. These observations do not support the suggested tentative formula " $\mathrm{Ba}_{2} \mathrm{Ti}_{2} \mathrm{O}_{5} \mathrm{CO}_{3}$ ", which supposes no cation segregation $(\mathrm{Ba}: \mathrm{Ti}=1: 1)$ in the crystalline regions. Based on high resolution and analytical electron microscopy and powder XRD phase analysis, we suggested in Ref. [15] the $\mathrm{BaO}-$ stabilized formation of barium carbonate, which alternatively can be referred to as barium oxycarbonate, with the crystal structure isotypical to the high-temperature calcite modification of $\mathrm{BaCO}_{3}$.

In this paper, we report further details on the crystal structure and some microstructural parameters of the possible barium oxycarbonate phase. An alternative mechanism of the stabilization of the high-temperature modification of $\mathrm{BaCO}_{3}$ is discussed as well, concerning the topotaxial formation of calcite-type structural domains by templating with oxygendeficient titanates, resulting in the oxide-carbonate intergrowth structures.

\section{Experimental}

Two complex precursors were used:

(i) barium titanium 1,2-ethanediolato complex (BTE): $\left[\mathrm{Ba}\left(\mathrm{C}_{2} \mathrm{H}_{6} \mathrm{O}_{2}\right)_{4}\right]\left[\mathrm{Ti}\left(\mathrm{C}_{2} \mathrm{H}_{4} \mathrm{O}_{2}\right)_{3}\right]$

(ii) barium titanyl oxalate (BTO): $\mathrm{BaTiO}\left(\mathrm{C}_{2} \mathrm{O}_{4}\right)_{2} * 4.5 \mathrm{H}_{2} \mathrm{O}$.

The preparation procedure of the precursors and their thermal decomposition to form intermediate products are described elsewhere $[15,28,29]$. These precursors were decomposed with a heating rate of $10 \mathrm{~K} \mathrm{~min}^{-1}$ up to $600{ }^{\circ} \mathrm{C}$.

Powder X-ray diffraction (XRD) patterns were recorded at $25^{\circ} \mathrm{C}$ and performed by a STADI MP diffractometer from STOE with a curved crystal germanium monochromator using Co-K $\alpha 1$ radiation $(1.78896 \mathrm{~A})$ and a degree step of 0.03 for $2 \theta$. The Fourier transformed infrared (FT-IR) spectra were recorded at $25{ }^{\circ} \mathrm{C}$ using a Mattson 5000 spectrometer (Mattson Instruments Inc., USA) in the range of $350-4000 \mathrm{~cm}^{-1}$ with a resolution of $2 \mathrm{~cm}^{-1}$ using $\mathrm{KBr}$ pellets.

\section{Results and discussion}

3.1. Formation of the metastable calcite-type $\mathrm{BaCO}_{3}$ in the intermediate Ba-rich phase

\subsubsection{Crystal structure and microstructural parameters}

The thermal decomposition of precursor complexes results in the component segregation in the intermediate stages (usually, between 400 and $600{ }^{\circ} \mathrm{C}$ ) [15]. As already mentioned above, the frequently observed specific XRD pattern (Fig. 1, top and middle) was previously attributed to some unknown barium titanium oxycarbonate with a tentative formula $\mathrm{Ba}_{2} \mathrm{Ti}_{2} \mathrm{O}_{5}\left(\mathrm{CO}_{3}\right)$ [24-28]. However, our latest results of the nanometer-resolved EFTEM and EELS analysis showed that the corresponding crystalline phase is Ba-rich and contains little or no titanium [15].

As demonstrated in Fig. 1, the positions and intensities of the observed diffraction maxima in powder XRD patterns of the intermediates (top curve BTE-derived, middle curve BTOderived) reveal a close correspondence to the calculated XRD pattern of the high-temperature modification of $\mathrm{BaCO}_{3}$ with calcite-type crystal structure (bars at the abscissa). The hkldependent observed shift of the diffraction maxima toward higher $2 \theta$ values implies, however, that some foreign atoms or atom groups are present in the crystal structure of calcite-type $\mathrm{BaCO}_{3}$ modifying the lattice parameters.

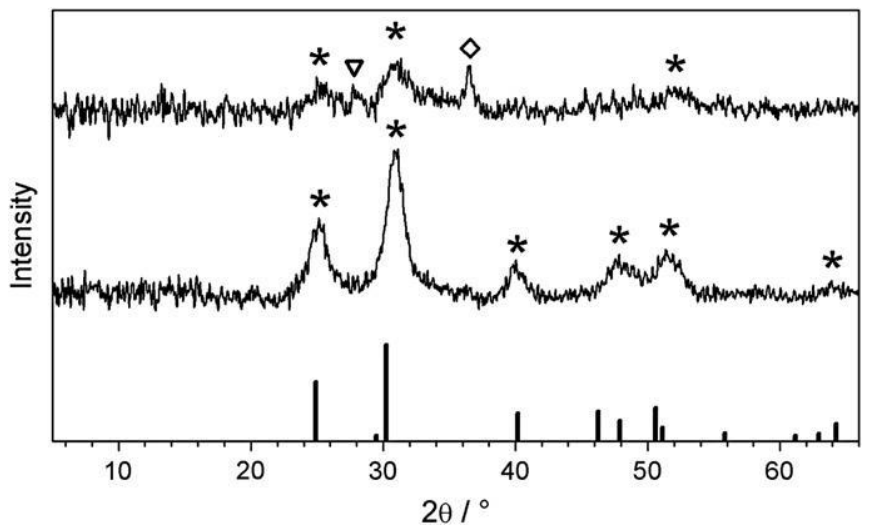

Fig. 1. Comparison of the experimentally observed powder XRD pattern for the BTE-derived (top) and BTO-derived (middle) intermediates with respect to the calculated positions of diffraction peaks and intensities for the calcitetype modification of pure $\mathrm{BaCO}_{3}$ (ICSD-27447; bars at the abscissa). The Barich phase is indicated by stars, the traces of whiterite by triangle, and the traces of $\mathrm{BaTiO}_{3}$ by rhombus. 
To investigate more precisely the structural differences of the observed $\mathrm{Ba}$-rich phase from the calcite-type modification of pure $\mathrm{BaCO}_{3}$, the full profile analysis of the observed powder XRD pattern, based on the Rietveld method [30-33] using the program FullProf [34], has been performed. The Rietveld method uses a least squares approach to refine a theoretical line of the XRD profile until it matches the measured profile whereas the peak positions are determined according to Bragg's law. The structure factor, the Lorentz factor, and the multiplicity of the reflections are taken into account for the estimation of the peak intensities, and the calculated reflections are convoluted with a function describing the peak shape to account for the characteristics of the beam, the experimental arrangement, and the sample size and shape.

The crystal structure of the calcite-type modification of $\mathrm{BaCO}_{3}$ was used as a starting model. Due to the low crystallinity of the sample, the diffraction peaks are broadened and poorly resolved. A low ratio of diffraction peak intensity to noise sets additional limitations on the precision of the refinement, predetermining rather high values of the agreement factors $R_{p}$ (for the profile) and $\mathrm{R}_{\mathrm{wp}}$ (for the weighted profile), which are influenced by the background. Nevertheless, some important information about the lattice symmetry, the unit cell, the atom position, and the microstructural parameters may be obtained in acceptable quality.

Fig. 2 presents the resulting calculated profile (continuous black line) in comparison with the measured X-ray data (red dots) with the difference shown below (blue), in case of BTOderived samples. It indicates that the diffraction pattern is well described within the same space symmetry group (R-3m) as the calcite-type $\mathrm{BaCO}_{3}$.

Table 1 summarises the calculated crystal structure and microstructural parameters. The agreement factors $\mathrm{R}_{\mathrm{B}}$ (for the Bragg reflections) and $\mathrm{R}_{\mathrm{f}}$ (for the crystallographic data) have been found to be quite reasonable ( $12.2 \%$ and $7.2 \%$, respectively), indicating a fairly good correspondence of the refined model with the observed powder XRD pattern. The relatively high $\mathrm{R}_{\mathrm{p}}$ and $\mathrm{R}_{\mathrm{wp}}$ values (22.1\% and $34.7 \%$, respectively) are caused by the above mentioned specific quality of the measured data, taking into account that the weighted profile agreement

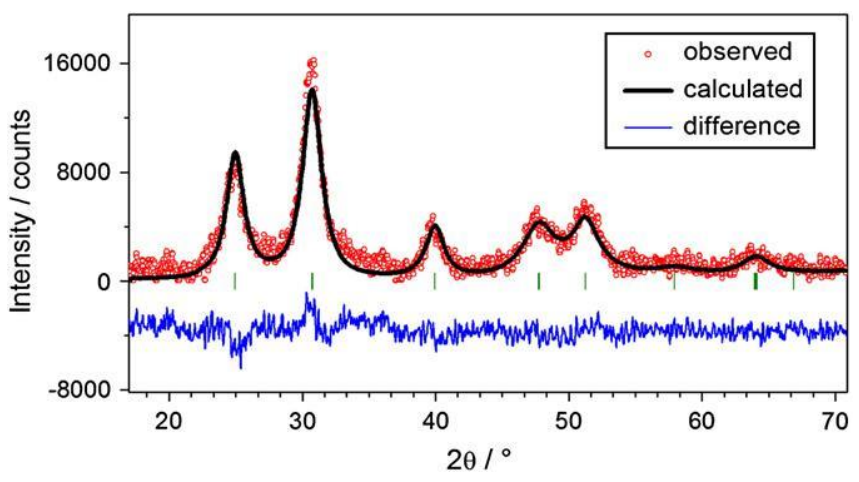

Fig. 2. Observed (red dots) and calculated (black line) powder XRD profile for BTO-derived intermediates with the difference below (where the zero line is shifted by 4000 counts).
Table 1

Crystal structure parameters calculated via Rietveld refinement of the powder XRD profile for the BTO-derived intermediates and related real structure data

Crystal structure parameters:

Formula unit

Crystal system

Space group

Unit cell dimensions

$\mathrm{BaCO}_{3}$

Trigonal

R-3m H (no. 166)

$\mathrm{a}=5.235(4) \mathrm{A}$

$\mathrm{c}=10.114(9) \mathrm{A}$

Unit cell volume

Z

$\mathrm{V}=240.1(3) \mathrm{A}$

3

Atom positions and occupation numbers (occupation numbers and oxygen positions are not refined in this work)

Ba 3 b 0.0000 .0000 .500 occ.: 1.0

C 3a 0.0000 .0000 .000 occ.: 1.0

O $18 f 0.2470 .0000 .000$ occ.: 0.5

Real structure data:

Average crystal domain size

$3.7 \pm 1 \mathrm{~nm}$ (anisotropic deviations)

Average value of maximum strain Agreement factors:

\begin{tabular}{ll}
$\mathrm{R}_{\mathrm{p}}$ & 0.221 \\
$\mathrm{R}_{\mathrm{wp}}$ & 0.347 \\
$\mathrm{R}_{\exp }$ & 0.021 \\
$\mathrm{R}_{\mathrm{B}}$ & 0.122 \\
$\mathrm{R}_{\mathrm{F}}$ & 0.072 \\
\hline
\end{tabular}

factor $\mathrm{R}_{\mathrm{wp}}$ is much higher as its calculated possible optimum value $\mathrm{R}_{\exp }(2.1 \%)$.

The calculated crystal structure parameters of the Ba-rich phase, also shown in Table 1, reveal a slight deviation of the unit cell dimensions, compared to those of the pure calcite-

type $\mathrm{BaCO}_{3}: \mathrm{a}=5.235(4) \mathrm{A}(+0.6 \%)$ and $\mathrm{c}=10.114(9) \mathrm{A}(-$ $4.3 \%)$.

Furthermore, information about the real structure of the crystalline phase in terms of crystallite size and crystal lattice strains can be provided, taking into account the instrumental resolution function of the diffractometer.

The anisotropic size of the crystallites (as coherently scattering domains) has been determined from the width of the Lorentzian component of the total pseudo-Voigt profile function, describing diffraction peaks. A general phenomenological model [35], using Scherrer's formula, was applied in this case, describing the size broadening as a linear combination of spherical harmonics. As shown in Table 1, the average size of the coherently scattering domains amounts to $3.7 \mathrm{~nm}$, with $1.0 \mathrm{~nm}$ anisotropy deviations. The maximum strain has been determined from the width of the Gaussian component of the total pseudoVoigt profile function, using a general model of the anisotropic strain of hexagonal symmetry [34]. In this way, we found the crystal structure of the Ba-rich phase to be strained along the [001] direction at most $(0.87 \%)$ and along the [110] direction at least $(0.12 \%)$; the average value of the maximum strain in the crystal structure being $0.57 \%$ (Table 1 ).

These results indicate (i) that the crystal structure of the Barich phase is very close to that of calcite-type $\mathrm{BaCO}_{3}$, and (ii) that the detected minor deviations occur predominantly along the [001] direction, revealing a lower lattice parameter and a higher strain. In the crystal structure of the calcite-type $\mathrm{BaCO}_{3}$ the atoms of different types are well separated in anionic 
and cationic layers, packed along [001], so that the deviations of the crystal structure parameters from that of pure $\mathrm{BaCO}_{3}$ can be explained by partial substitutions within these layers.

Not only the described deviations of the lattice parameters and the occurrence of microstrains point to any substitutions in the crystal structure of the calcite-type $\mathrm{BaCO}_{3}$; moreover, Table 2 presents the calculated relative peak intensities for the BTO-derived calcite-type $\mathrm{BaCO}_{3}$, together with the observed relative intensities, for comparison. The observed slight deviations of the calculated intensities from the observed values for some diffraction peaks (cf. Fig. 2 and Table 2) provide an additional evidence of slightly changed crystallographic structure factors, due to possible substitution effects in the ideal structure of the calcite-type $\mathrm{BaCO}_{3}$, the details of which are discussed in Sections 3.2 and 3.3.

\subsubsection{IR spectroscopy}

The results of our IR investigations provide further evidence of the formation of the calcite-type barium carbonate in the intermediate products of the thermal decomposition of the precursor complexes.

Fig. 3 presents the measured IR vibration modes for the calcite-type Ba-rich intermediate phase, occurring at 1753, 1390-1435, 1064, 876, and $693 \mathrm{~cm}^{-1}$, together with the IR spectrum of aragonite-type $\mathrm{BaCO}_{3}$ having bands at $1752\left(v_{\mathrm{s}}+\right.$ $\mathrm{d}_{\text {oop}}$,

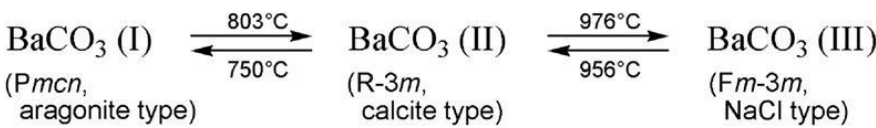

$1454 / 1437\left(v_{\mathrm{as}}\right), 1059\left(v_{\mathrm{s}}\right), 856\left(\delta_{\text {oop }}\right)$ and $692\left(\delta_{\mathrm{ip}}\right) \mathrm{cm}^{-1}$ [36]. A comparison of both spectra shows that the position of the out-ofplane deformation mode is clearly shifted from $856 \mathrm{~cm}^{-1}$ (aragonite-type $\mathrm{BaCO}_{3}$ ) to $876 \mathrm{~cm}^{-1}$ (calcite-type intermediate product), according to similar observations reported in Refs.

Table 2

Calculated diffraction peak positions and relative intensities for the BTO-derived calcite-type $\mathrm{BaCO}_{3}$, and the observed relative intensities for comparison

\begin{tabular}{lllll}
\hline $\mathrm{hkl}$ & $2 \theta\left(^{\circ}\right)$ & $\mathrm{I}_{\text {calc. }}(\%)$ & $\mathrm{I}_{\text {obs. }}(\%)$ & $\mathrm{d}_{\text {hkl }}(\AA)$ \\
\hline 101 & 24.98 & 62 & 61 & 4.1367 \\
012 & 30.74 & 100 & 100 & 3.3754 \\
003 & 30.78 & 6 & 5 & 3.3709 \\
110 & 39.97 & 29 & 26 & 2.6173 \\
021 & 47.71 & 20 & 19 & 2.2118 \\
104 & 47.80 & 28 & 25 & 2.2080 \\
202 & 51.25 & 14 & 13 & 2.0684 \\
113 & 51.28 & 32 & 31 & 2.0673 \\
015 & 57.93 & 7 & 7 & 1.8470 \\
211 & 63.94 & 10 & 14 & 1.6894 \\
024 & 64.01 & 7 & 7 & 1.6877 \\
006 & 64.11 & 5 & 5 & 1.6854 \\
122 & 66.90 & 6 & 8 & 1.6228 \\
\hline
\end{tabular}

[26-28,37]. In general, the shift in the position of this mode may be used for carbonates as indicator for changing the crystallographic environment (site symmetry) of the $\mathrm{CO}_{3}{ }^{2-}$ anion [38]. This effect can be clearly observed, e.g., in the spectra of calcite and aragonite modifications of $\mathrm{CaCO}_{3}$ (Table 3) $[39,40]$, as calcite shows this mode at $879 \mathrm{~cm}^{-1}$, and aragonite at $866 \mathrm{~cm}^{-1}$, reflecting the difference in the site symmetry: Calcite-type $\mathrm{CaCO}_{3}$ crystallizes in the space group $\mathrm{D}_{3 \mathrm{~d}}^{6}$ (R$3 \mathrm{c}$ ), and the site symmetry of the carbonate ion is $\mathrm{D}_{3}$, according to Halford's rules [41], while aragonite-type $\mathrm{CaCO}_{3}$ crystallizes in the space group $\mathrm{D}_{2 \mathrm{~h}}^{16}(\mathrm{Pmcn})$, and the site symmetry of this carbonate ion is $\mathrm{C}_{\mathrm{S}}$.

In addition, we observed for the calcite-type Ba-rich intermediate phase an IR activity of the symmetric stretching mode $\mathrm{n}_{1}$ at $1064 \mathrm{~cm}^{-1}$, which is not observed in the calcite modification of $\mathrm{CaCO}_{3}$ [39]. This fact may be explained by the known disordering of $\mathrm{CO}_{3}^{2-}$ anions in the calcite-type $\mathrm{BaCO}_{3}$, which reduces the symmetry of the anionic site from $\mathrm{D}_{3}$ to $\mathrm{C}_{3 \mathrm{v}}$, enabling thus the IR activity of the $\mathrm{n}_{1}$ normal mode (see Table 3).

\subsection{Structural relations of $\mathrm{BaCO}_{3}$ and a possible barium} oxycarbonate $\mathrm{BaO}_{\mathrm{x}}\left(\mathrm{CO}_{3}\right)_{1-\mathrm{x}}$

Three modifications of barium carbonate are presently known from the literature [43]:

The aragonite-type modification, based on the hexagonal packing of Ba layers, is the only one stable under normal conditions. Two other modifications of $\mathrm{BaCO}_{3}$, calcite-type and $\mathrm{NaCl}$-type, are reversibly formed above 800 and $970{ }^{\circ} \mathrm{C}$,

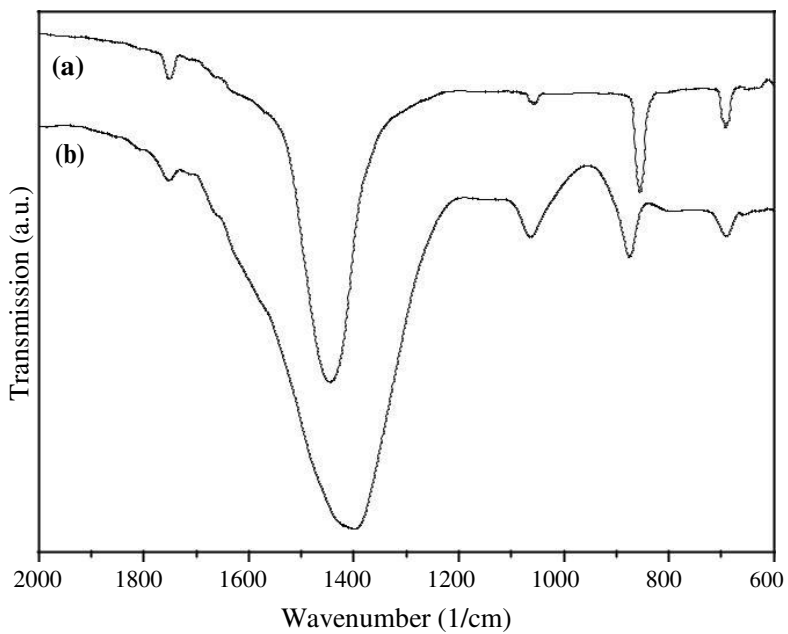

Fig. 3. IR spectra of aragonite-type $\mathrm{BaCO}_{3}$ (a) and BTO-derived intermediate product (b). 
Table 3

$\underline{\text { IR spectra of some carbonates }\left(\mathrm{cm}^{-1}\right)}$

\begin{tabular}{|c|c|c|c|c|c|}
\hline Compound & $\begin{array}{l}\mathrm{CO}_{3}{ }^{2-} \text { - site } \\
\text { symmetry }\end{array}$ & $\begin{array}{l}\mathrm{n}_{1} \\
\left(\mathrm{v}_{\mathrm{S}}\right) \\
\end{array}$ & ( $\mathrm{n}_{2}$ oop & $\begin{array}{l}\mathrm{n}_{3} \\
\left(\mathrm{v}_{\mathrm{as}}\right)\end{array}$ & $\begin{array}{l}\mathrm{n}_{4} \\
\left(\delta_{\mathrm{ip}}\right)\end{array}$ \\
\hline Free $\mathrm{CO}_{3}{ }^{2-}$ ion [42] & $\mathrm{D}_{3 \mathrm{~h}}$ & - & 879 & 1415 & 680 \\
\hline Calcite [39] & $\mathrm{D}_{3}$ & - & 879 & $1429-1492$ & 706 \\
\hline Aragonite [39] & $\mathrm{C}_{\mathrm{s}}$ & 1080 & 866 & $1504 / 1492$ & $711 / 706$ \\
\hline Whiterite & $\mathrm{C}_{\mathrm{S}}$ & 1059 & 856 & $1454 / 1437$ & 692 \\
\hline BTO intermediate & $c_{3 v}$ & 1064 & 876 & $1435-1390$ & 693 \\
\hline
\end{tabular}

respectively [43]. These are based on the cubic packing of the barium layers as schematically shown in Fig. 4.

There is no possibility to obtain high-temperature modifications of pure $\mathrm{BaCO}_{3}$ in the metastable state at room temperature. The phase transition temperature shows a slight hysteresis loop, and at least at $750 \mathrm{C}$ a room-temperature aragonite-type modification of $\mathrm{BaCO}_{3}$ is formed [43]. However, there are some indications in the literature $[43,44]$ that different intentional or unintentional impurities in $\mathrm{BaCO}_{3}$ can stabilize the hightemperature modification of barium carbonate down to significantly lower temperatures, in some cases also down to room temperature. For instance, due to the doping of barium carbonate with $\mathrm{BaSO}_{4}$ (up to $10 \mathrm{~mol} \%$ ), barium carbonate can be obtained in its metastable state at room temperature [44]. Accordingly, in Ref. [43] it is reported, that the heating of a mixture of $\mathrm{BaCO}_{3}$, $\mathrm{SrCO}_{3}$ and $\mathrm{CaCO}_{3}$ above $750{ }^{\circ} \mathrm{C}$ resulted in a mixed carbonate phase of the calcite-type structure, which remained unchanged at room temperature.

It is worthwhile to discuss, why the high-temperature calcitetype modification of $\mathrm{BaCO}_{3}$ forms at the intermediate stages of the thermal decomposition of the precursor complexes at a relatively low temperature $\left(600{ }^{\circ} \mathrm{C}\right.$, compared to $803^{\circ} \mathrm{C}$ for pure $\mathrm{BaCO}_{3}$ ) and remains stable at room temperature for a long time. On the one hand, the aragonite-type modification of pure $\mathrm{BaCO}_{3}$ is thermodynamically more stable, having a higher density of atomic packing. The columnar arrangement of the $\mathrm{CO}_{3}{ }^{2-}$ anions, appearing in this case, is, however, not favoured, due to the mutual electrostatic repulsion between neighbouring anions. This repulsion can be partially relieved by a skew-orientation of neighbouring $\mathrm{CO}_{3}{ }^{2-}$ anions to each other, as observed in the fully ordered room-temperature modification of $\mathrm{BaCO}_{3}$, demonstrated in Fig. 5A. At higher temperatures (smearing of atomic positions due to thermally initiated rotation of anions) or due

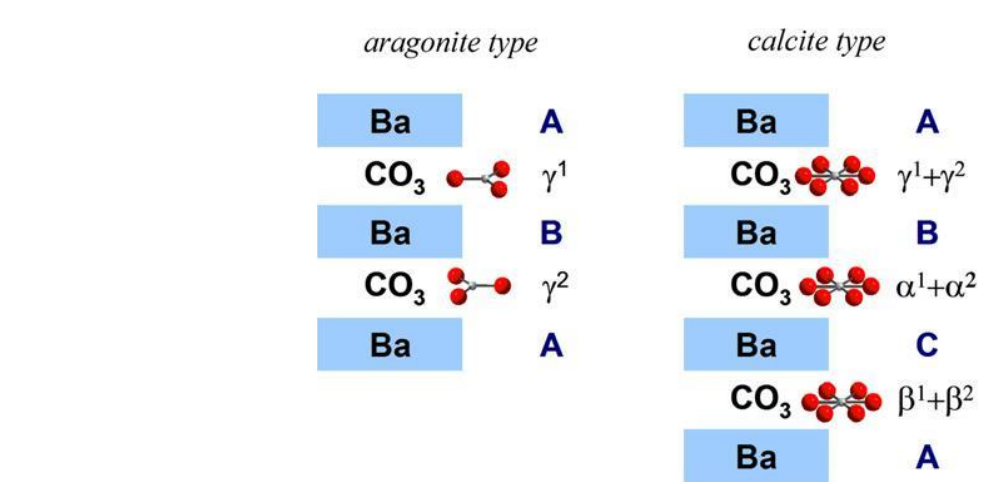

to substitutions in the anionic sublattice (introduction of anions with different geometry), the repulsion between neighbouring anions in the aragonite-type structure becomes higher, so that less dense crystal structure types, but without columnar arrangement of anions (cf. Fig. 5B), become thermodynamically more favourable. Thus, a substitution of $\mathrm{CO}_{3}{ }^{2-}$ in the anionic sublattice by $\mathrm{O}^{2-}$ between 400 and $600 \mathrm{C}$ (the temperatures of the intermediate stage of the thermal decomposition of the precursor complexes) can be assumed, implying a stabilization of the calcite-type $\mathrm{BaCO}_{3}$ modification.

Related Rietveld calculations concerning the degree of the supposed substitution of $\mathrm{CO}_{3}{ }^{2-}$ by $\mathrm{O}^{2-}$ anions via the oxygen positions in the crystal lattice or the occupation factors of the carbon and oxygen atomic sites, would be clearly of limited value, due to the low crystallinity of the Ba-rich phase. In-stead, we have estimated the possible degree of $\mathrm{CO}_{3}{ }^{2-}$ substitution by $\mathrm{O}^{2-}$ anions from the varying lattice parameters using Vegard's law, as illustrated in Fig. 6. The reduced unit cell volumes (as unit cell volume $\mathrm{V}$ divided by the number of formula units $\mathrm{Z}$ ) of pure calcite-type $\mathrm{BaCO}_{3}$ (ICSD-27447), $\mathrm{BaO}$ (ICSD-58663) and the calculated reduced unit cell volume of about $80 \mathrm{~A}$ for the calcite-type phase, determined by the Rietveld method (see Table 1 ), were used. The estimated chemical composition of the Ba-rich phase corresponds to composition of $\mathrm{BaO}_{0.06}\left(\mathrm{CO}_{3}\right)_{0.94}$, implying that ca. $6 \%$ of the anions are substituted in the crystal structure of calcite-type $\mathrm{BaCO}_{3}$, representing thus a barium oxycarbonate phase.

The degree of the anionic substitution in the calcite-type $\mathrm{BaCO}_{3}$ is evidently not always the same over the bulk of the sample, which is evidenced by the detected high rate of microstrains in the crystal structure and by the slightly varying lattice parameters in different samples, prepared by thermal decomposition of the precursor complexes and containing amounts of the crystalline Ba-rich phase. In some samples the degree of the anionic substitution reached $15 \%$, as determined from the corresponding lattice parameter variations according to Vegard's law.

\subsection{Templating of calcite-type $\mathrm{BaCO}_{3}$ with oxygen-deficient titanate interfaces}

By series of preparation batches with different titanium contents we have observed that the formation of the calcite-type

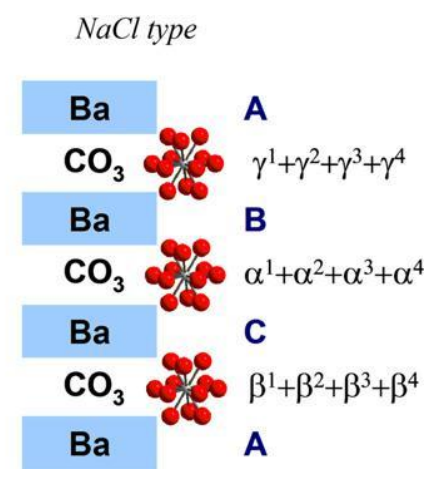

Fig. 4. The packing features of different polymorphs of $\mathrm{BaCO}_{3}$. The relative orientations (not positions) of anions $\mathrm{CO}_{3}{ }^{2-}$ are additionally shown in the scheme to illustrate the "smearing" of the $\mathrm{CO}_{3}{ }^{2-}$ anion over symmetry-equivalent positions due to its thermally activated rotation. 

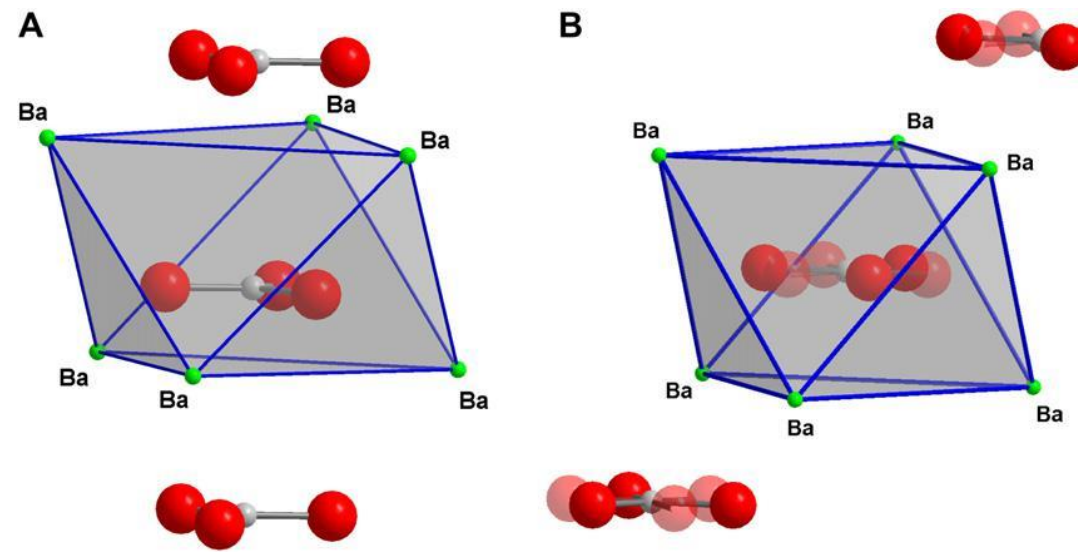

Fig. 5. The relative positions and orientations of the neighbour anions (in the second coordination sphere) around the $\mathrm{CO}_{3}{ }^{2-}$ anion in $(\mathrm{A})$ aragonite-type $\mathrm{BaCO}_{3}$ and (B) calcite-type $\mathrm{BaCO}_{3}$. (Three oxygen atoms are statistically distributed over six symmetry-equivalent positions around carbon in calcite-type $\mathrm{BaCO}$.)

$\mathrm{BaCO}_{3}$ occurs preferably in the presence of titanium in the chemical system. This suggests a further possible alternative mechanism which can contribute to the stabilization of the calcite-type modification of $\mathrm{BaCO}_{3}$ : the topotaxial formation of calcite-type structural domains of $\mathrm{BaCO}_{3}$ by templating with oxygen-deficient titanates, resulting in the oxycarbonate inter-growth structures. In the following, the details of this mechanism will be discussed.

The preferred ccp ordering of Ba atoms compared to the hcp ordering can be supported, e.g., at the interfaces with cubic$\mathrm{BaTiO}_{3}$. However, for this purpose, oxygen vacancies have to be present in the interfacial titanate layers, to provide the necessary tetragonal-pyramidal coordination of the titanium atoms and herewith the free docking places for the $\mathrm{CO}_{3}{ }^{2-}$ anions. The presence of the oxygen vacancies implies a lower oxidation state of +3 for the interfacial titanium atoms. Fig. 7 presents a suggested model for such a templating, derived from the wellknown structural family of the Ruddlesden-Popper perovskitebased oxycarbonates of the type $\mathrm{A}_{4}{ }_{4} \mathrm{~B}^{\mathrm{III}}{ }_{2} \mathrm{O}_{6}\left(\mathrm{CO}_{3}\right)$, familiar for some transition metals, but not yet described for titanium, and from solid solutions of these oxycarbonates

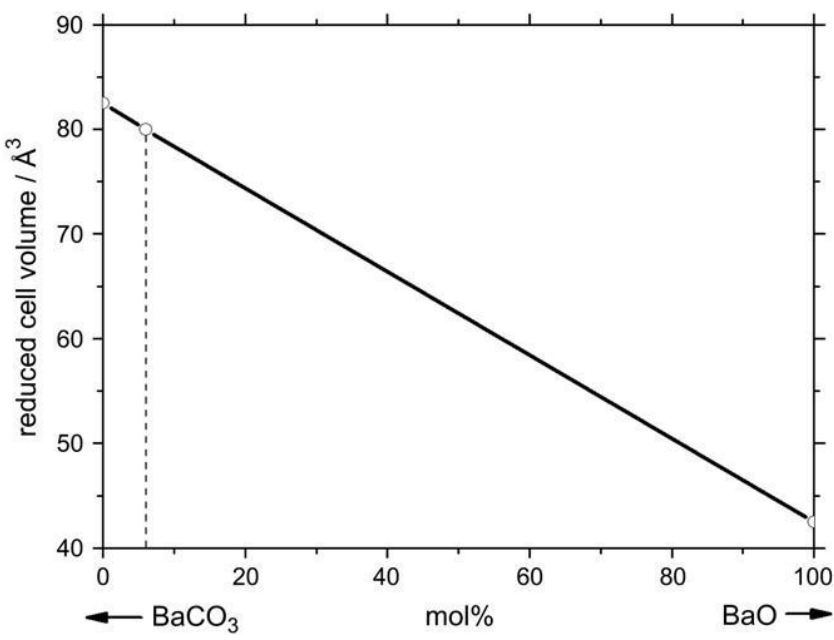

Fig. 6. Application of Vegard's law to determine the degree of anionic substitution of $\mathrm{CO}_{3}{ }^{2-}$ by $\mathrm{O}^{2-}$ in calcite-type $\mathrm{BaCO}_{3}$ formed at the intermediate stage of the thermal decomposition of the precursor complexes. with corresponding $\mathrm{A}_{4}{ }_{4} \mathrm{~B}^{\mathrm{IV}}{ }_{3} \mathrm{O}_{10}$ RuddlesdenePopper perovskites (see Section 1). The layer of $\mathrm{Ba}^{2+}$ cations is interfaced with the layer of $\mathrm{Ti}^{3+}$ and $\mathrm{O}^{2-}$ ions lying in the same plane (con-sider the base of the tetragonal $\mathrm{TiO}_{5}$-pyramid at the interface, Fig. 7). The shortest $\mathrm{Ba}-\mathrm{Ti}$ interatomic distances are significantly longer, compared to $\mathrm{Ba}-\mathrm{O}$ (ca. a factor of 1.22), so that no bonding between $\mathrm{Ba}$ and $\mathrm{Ti}$ is possible. We do not pro-vide any absolute values for the interatomic distances at this point, as the suggested model structure serves rather to illustrate the proposed atomic packing by the intergrowth with titanates. The simplest intergrowth structure with a smallest lamella of $\mathrm{BaCO}_{3}$ and titanate is shown in Fig. 8, demonstrating that all titanium atoms in this structure are in the oxidation state +3 , and that the titanate blocks are monoclinically distorted, regarding the observed rhombohedral distortion of the calcite-type $\mathrm{BaCO}_{3}$ blocks. The additional $\mathrm{Ti}^{4+}$-containing perovskite blocks or the $\mathrm{BaO}$ blocks can be introduced in these titanate layers. The described mechanism leads thus to the formation of an oxycarbonate, resulting from the intergrowth of carbonate and oxide (i.e. titanate) building units.

Our observation that the formation of the crystalline intermediate is directly related to the presence of $\mathrm{Ti}^{3+}$ as well as the suggested topotaxial templating mechanism is also in accordance with Cho [45], who reports on XPS analyses performed

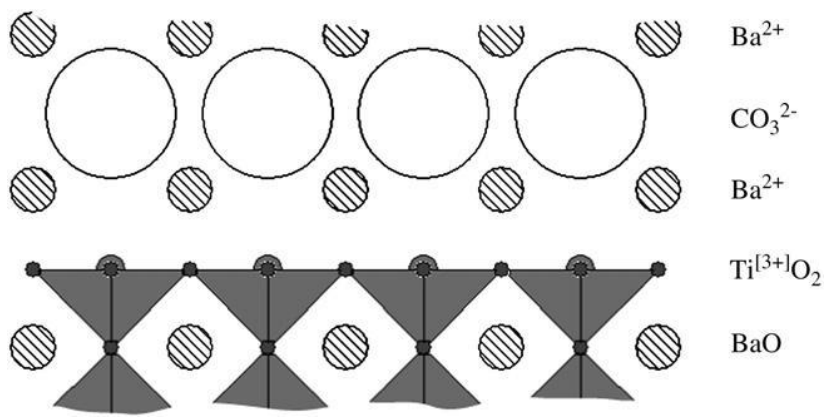

Fig. 7. Suggested model for the templating mechanism for the growth of $\mathrm{BaCO}_{3}$ with ccp ordering of $\mathrm{Ba}$ atoms (calcite-type related structure) on the oxygen-deficient titanate interface. In titanate block, the oxygen atoms are implied in vertices of grey polyhedra; $\mathrm{CO}_{3}{ }^{2-}$ anions are schematically shown with large circles in the carbonate block. 


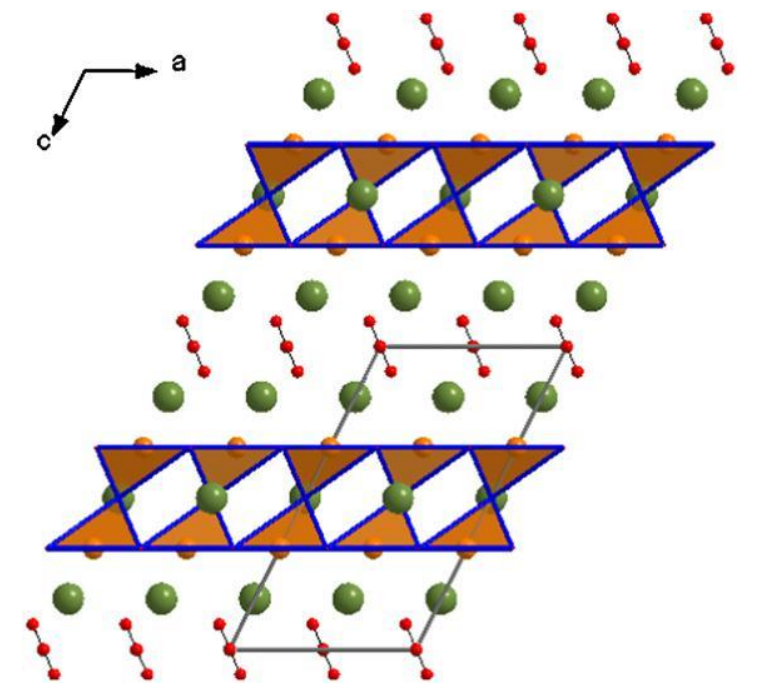

Fig. 8. Suggested simplest structure of the intergrowth of $\mathrm{BaCO}_{3}$ layers with the titanate layers $(\mathrm{Ba}$ - green; $\mathrm{Ti}$ atoms and polyhedra - orange; $\mathrm{C}$ - grey; $\mathrm{O}$ red; besides the oxygen atoms are implied (not explicitly shown as balls) in vertices of the distorted tetragonal $\mathrm{TiO}_{5}$-pyramids).

at (Ba,Ti)-oxalates decomposed at $500{ }^{\circ} \mathrm{C}$. Up to $40 \%$ of the titanium atoms may be reduced to the oxidation state +3 , and at higher decomposition temperatures (over $600 \mathrm{C}$ ) practically no $\mathrm{Ti}^{3+}$ was detected in the intermediate samples.

\section{Conclusion}

The formation processes of the crystalline intermediate phase, observed during thermal decomposition of the precursor complexes in the temperature range of $400-600{ }^{\circ} \mathrm{C}$, were investigated. XRD phase analysis and IR spectroscopy evidenced the intermediate formation of calcite-type barium carbonate. Rietveld refinement of the crystal structure data provided detailed information about lattice parameter and the real structure of the crystalline phase in terms of crystallite size and lattice strains. The occurrence of the metastable calcite phase is explained by the stabilization of this modification in the form of an oxycarbonate phase down to room temperature. Two alternative mechanisms of this stabilization are proposed: (i) partial substitution of $\mathrm{CO}_{3}{ }^{2-}$ for $\mathrm{O}^{2}$ in the anionic sublattice, leading to the formation of barium oxycarbonate, and (ii) templating of ccp-based ordering of $\mathrm{Ba}$ atoms, which occurs in the calcite-type $\mathrm{BaCO}_{3}$ by oxygendeficient titanate interfaces, leading to the topotaxial formation of crystalline domains of the calcite phase and resulting in the oxidecarbonate intergrowth structures. In this process, the presence of the oxygen vacancies results in a lower oxidation state of +3 for the interfacial titanium atoms. We suggest a model for such a topotaxial process enabling that the titanate blocks are monoclinically distorted, according to the observed rhombohedral distortion of the calcite-type barium carbonate blocks.

\section{References}

[1] K. Kinoshita, T. Yamada, Nature 357 (1992) 313.
[2] Y. Miyazaki, H. Yamane, T. Hirai, Physica C 198 (1992) 53.

[3] J. Akimitsu, M. Uehara, M. Ogawa, H. Nakata, K. Tomimoto, Y. Miyazaki, H. Yamane, T. Hirai, K. Kinoshita, Y. Matsui, Physica C 201 (1992) 320

[4] T. Den, T. Kobayashi, J. Akimitsu, Physica C 208 (1993) 351.

[5] B. Domenges, M. Hervieu, B. Raveau, Physica C 207 (1993) 65.

[6] Y. Matsui, J. Akimitsu, Micros. Res. Tech. 30 (1995) 155.

[7] O.-K. Moune-Minn, P. Caro, J. Crystallogr. Res. 12 (1982) 157.

[8] J. Ho"lsa", T. Turkki, Thermochim. Acta 190 (1991) 335.

[9] S. Tamura, K. Koyabu, T. Masui, N. Imanaka, Chem. Lett. 33 (2004) 58.

[10] T. Masui, K. Koyabu, S. Tamura, N. Imanaka, J. Mater. Sci. 40 (2005) 4121.

[11] Y. Mayama, K. Koyabu, T. Masui, S. Tamura, N. Imanaka, J. Alloys Compd. 418 (2006) 243.

[12] K. Koyabu, Y. Mayama, T. Masui, N. Imanaka, J. Alloys Compd. 418 (2006) 230.

[13] N. Imanaka, M. Kamikawa, G. Adachi, Electroanalysis 13 (2001) 1291.

[14] N. Imanaka, A. Ogura, M. Kamikawa, G. Adachi, Electrochem. Commun. 3 (2001) 451.

[15] V. Ischenko, E. Pippel, R. Ko" ferstein, H.-P. Abicht, J. Woltersdorf, Solid State Sci. 9 (2007) 21.

[16] K. Yamaura, Q. Huang, J.W. Lynn, R.W. Erwin, R.J. Cava, J. Solid State Chem. 152 (2000) 374.

[17] Y. Breard, C. Michel, M. Hervieu, B. Raveau, J. Mater. Chem. 10 (2000) 1043

[18] Y. Breard, C. Michel, M. Hervieu, N. Nguyen, F. Studer, A. Maignan, B. Raveau, F. Bouree, J. Solid State Chem. 170 (2003) 424.

[19] A. Baszczuk, M. Wolcyrz, A. Zygmunt, J. Alloys Compd. 360 (2003) 1.

[20] Y. Breard, C. Michel, A. Maignan, F. Studer, B. Raveau, Chem. Mater. 15 (2003) 1273.

[21] B. Raveau, M. Hervieu, D. Pelloquin, C. Michel, R. Retoux, Z. Anorg. Allg. Chem. 631 (2005) 1831.

[22] S.N. Ruddlesden, P. Popper, Acta Crystallogr. 10 (1957) 538.

[23] S.N. Ruddlesden, P. Popper, Acta Crystallogr. 11 (1958) 54.

[24] M. Rajendran, M.S. Rao, J. Mater. Res. 12 (1997) 2665.

[25] P. Duran, F. Capel, D. Gutierrez, J. Tartaj, M.A. Banares, C. Moure, J. Mater. Chem. 11 (2001) 1828

[26] P. Duran, D. Gutierrez, J. Tartaj, M.A. Banares, C. Moure, J. Eur. Ceram. Soc. 22 (2002) 797.

[27] S. Gablenz, H.-P. Abicht, E. Pippel, O. Lichtenberger, J. Woltersdorf, J. Eur. Ceram. Soc. 20 (2000) 1053.

[28] R. Köferstein, L. Ja"ger, V. Lorenz, H.-P. Abicht, J. Woltersdorf, E. Pippel, H. Görls, Solid State Sci. 7 (2005) 1280.

[29] W.S. Clabaugh, E.M. Swiggard, R. Gilchrist, J. Res. Nat. Bur. Std. 56 (1956) 289.

[30] H.M. Rietveld, J. Appl. Crystallogr. 22 (1967) 151.

[31] H.M. Rietveld, J. Appl. Crystallogr. 2 (1969) 65.

[32] G. Malmros, J.O. Thomas, J. Appl. Crystallogr. 10 (1977) 7.

[33] C.P. Khattak, D.E. Cox, J. Appl. Crystallogr. 10 (1977) 405.

[34] J. Rodriguez-Carvajal, Physica B 192 (1993) 55.

[35] M. Jarvinen, J. Appl. Crystallogr. 26 (1993) 527.

[36] B.M. Gatehouse, S.E. Livingstone, R.S. Nyhlom, J. Chem. Soc. (1958) 3137.

[37] H.S. Gopalakrishnamurthy, M. Subba Rao, T.R. Narayanan Kutty, J. Inorg. Nucl. Chem. 37 (1975) 891.

[38] P.C. Healy, A.H. White, Spectrochim. Acta 29A (1973) 1191.

[39] K. Nakamoto, Infrared and Raman Spectra of Inorganic and Coordination Compounds, John Wiley \& Sons, USA, 1986.

[40] J.M. Hunt, M.P. Wisherd, L.C. Bonham, Anal. Chem. 22 (1950) 1478.

[41] R.S. Halford, J. Chem. Phys. 14 (1946) 8.

[42] G. Herzberg, Infrared and Raman Spectra of Polyatomic Molecules, D. Van Nostrand Company, USA, 1947.

[43] J.J. Lander, J. Chem. Phys. 17 (1949) 829.

[44] T. Nishino, T. Sakurai, N. Ishizawa, N. Mizutani, M. Kato, J. Solid State Chem. 69 (1987) 24

[45] W.-S. Cho, J. Phys. Chem. Solids 59 (1998) 659. 